\title{
Comparing the Efficacy of Patelet-rich Plasma (PRP) versus Tranexamic Acid (4mg/mL) as Intradermal Treatments of Melasma
}

\author{
Maryam Mumtaz, Tahir Hassan Chandio, Mohammad Khurram Shahzad, Nazia Hanif, Sarah Anwar and Saira \\ Rafique
}

Department of Dermatology, Sheikh Zaid Hospital, Rahim Yar Khan, Pakistan

\begin{abstract}
Objective: To compare the efficacy of intradermal platelet-rich-plasma vs. intradermal tranexamic acid in treatment of melasma.

Study Design: Non-randomised controlled trial.

Place and Duration of Study: Sheikh Zayed Hospital, Rahim Yar Khan from $1^{\text {st }}$ October 2019 to $30^{\text {th }}$ April 2020.

Methodology: Cases of melasma from either gender with age 20-40 years, were included. Diagnosis of melasma was made clinically on the basis of hyperpigmentation at sun-exposed areas and by Wood's lamp. Severity was labelled on the basis of melasma area and severity index (MASI) score. Cases in group A were managed with $1 \mathrm{ml}$ of intradermal platelet-rich plasma (PRP) and those in group B were offered intradermal tranexamic acid in a dose of 4 mg. The treatment was offered every $4^{\text {th }}$ week and for a total period of 12 weeks; and final outcome was seen at $24^{\text {th }}$ week. At every visit, the cases were noted for their mean MASI score.

Results: In this study, there were a total of 64 cases, 32 in each group. There were 19 (59.38\%) males in group A and 16 $(50 \%)$ in group $B(p=0.61)$. Mean age in group A and B was $24.63 \pm 9.87$ vs. $23.94 \pm 8.93$ years $(p=0.76)$. Mean MASI score at baseline was $29.84 \pm 5.14$ vs. $29.56 \pm 4.39, p=0.21$. MASI was significantly better in group A at 4 weeks where score was $29.44 \pm 5.35$ vs. $28.69 \pm 4.10, p=0.01$. Mean MASI was $12.81 \pm 1.78$ vs. $18.38 \pm 3.50, p=00001$ at 12 weeks and $8.72 \pm 3.40$ vs. $14.97 \pm 4.33, p=0.02$ at 24 weeks in group $A$ and $B$, respectively.
\end{abstract}

Conclusion: Intradermal PRP is significantly better than intradermal tranexamic acid in management of melasma.

Key Words: Melasma, Tranexamic acid, PRP, MASI.

How to cite this article: Mumtaz M, Chandio TH, Shahzad MK, Hanif N, Anwar S, Rafique S. Comparing the Efficacy of Patelet-rich Plasma (PRP) versus Tranexamic Acid $(4 \mathrm{mg} / \mathrm{mL})$ as Intradermal Treatments of Melasma. J Coll Physicians Surg Pak 2021; 31(05):502-505.

\section{INTRODUCTION}

Melasma is not an uncommon presentation to the dermatology outpatient clinics; and is defined as an acquired hyper melanosis observed in sun-exposed areas. It is more commonly observed at the cheeks, forehead, chin, lips and neck region. Presentation at other sun-exposed areas is not rare too. ${ }^{1,2}$

It is usually asymptomatic and the management is needed due to cosmetic reasons. It is more common in females, especially in the pregnancy. It can be broadly classified as centro-facial, malar and mandibular. On the basis of Wood's lamp examination, it is labelled as epidermal, dermal and mixed. ${ }^{3}$

Correspondence to: Dr. Maryam Mumtaz, Department of Dermatology, Sheikh Zaid Hospital, Rahim Yar Khan, Pakistan

E-mail: maryammumtaz@hotmail.com

Received: November 06, 2020; Revised: March 27, 2021; Accepted: April 02, 2021

DOI: https://doi.org/10.29271/jcpsp.2021.05.502
The basic underlying pathophysiology is not well understood. Hormonal imbalance, especially oestrogen in females, is thought to be an important predictor. The higher incidence in cases using oral contraceptive pills (OCPs) also favours the hormonal aetiology. Photosensitisation effect of certain drugs, thyroid disorders and ovarian abnormalities are also thought to be associated with this presentation. ${ }^{3,4}$

Ultraviolet (UV) radiations in the sunlight is one of the commonest agreed factors known for production of alpha melanocyte-stimulating hormone and corticotropin, as well as interleukin 1 and endothelin 1, all of which contribute to increased melanin production by intra-epidermal melanocytes. ${ }^{5,6}$

The diagnosis is usually clinical and on examination. There is hyperpigmentation that is usually tan or bluish and strong history of OCPs use or pregnancy is usually suggestive. Supportive therapies like avoidance of sun-exposure and use of certain sun-blocks can be helpful in decreasing the progression of disease, but definitive therapy needs active intervention; for which, various drugs have been tried with varying degree of 
success rate and side effect profiles. ${ }^{7}$ Platelets are enriched with poly type granules, which can lead to a cascade of reactions. The major pathology relies upon inhibition of melanin synthesis via altered activity of extracellular kinases and prostaglandins E2 (PGE2). ${ }^{8,9}$

Tranexamic acid is a fibrinolytic agent that has anti-plasmin properties. Tranexamic acid can inhibit the paracrine melanogenic factors that normally act to stimulate melanocytes. ${ }^{10}$

Tranexamic acid is amongst the most widely used drug in various forms like topical preparations and intradermal injections either alone or in combination of other agents. ${ }^{10}$ Platelet rich plasma is extensively used in recent times for various entities and is also being use for melasma with good results. But local data is lacking. This study was conducted to compare the efficacy of PRP and tranexamic acid for intradermal treatment of melasma.

\section{METHODOLOGY}

This was a non-randomised controlled trial that was carried out from $1^{\text {st }}$ October 2019 to $30^{\text {th }}$ April 2020 at the OutpatientDepartment of Dermatology, Sheikh Zayed Hospital, Rahim Yar Khan. The inclusion criteria comprised of cases of either gender with age range of 20 to 40 years suffering from melasma. The diagnosis of melasma was made clinically on the basis of hyperpigmentation at sun-exposed areas and Wood's lamp examination. An informed consent was taken from each subject to include in this study and explained about the potential side effect of the drug/therapies, and ensured the confidentiality of the data. The detailed demographic and clinical data was recorded regarding age, gender, duration of melasma and severity of melasma labelled on the basis of standard MASI score. ${ }^{11}$ Exclusion criteria included pregnancy, patients with known platelet dysfunction, patients with local inflammatory skin disorder and those with prior history of allergy to tranexamic acid.

After explaining all the procedure to the subjects, face was washed thoroughly using soap and plenty of water. Topical anaesthetic cream anestin (10.56\% lidocaine) was applied on face for 45 minutes and then wiped off to obtain completely dry skin. Then these cases were divided into two equal groups by simple lottery method with a ration of $1: 1$ as group $A$ and $B$ via non-probability consecutive sampling.

The sample size was calculated as 64 (32 in each group) by keeping the confidence level equal to $95 \%$, power equal to $90 \%$ and the excellent response in PRP group as $47.8 \%$ and in tranexamic acid as $13 \%$ in previous studies. ${ }^{12}$ A total of 97 cases were assessed, 64 fulfilled the criteria ( 32 in each group). There were no loss-to-follow up in any cases and final data was assessed on same 64 cases.

In group A patients, 15-20 ml of blood was taken in a tube having sodium citrate anticoagulant. PRP was obtained manually by a two-step procedure using a centrifuge machine. First spin was performed at 1500 RPM for 10 minutes. Second spin was performed at a rate of 4000 RPM for 10 minutes. Thus obtaining a two-part plasma. Upper $2 / 3^{\text {rd }}$ was platelet-poor plasma (PPP) and was discarded. Lower $1 / 3^{\text {rd }}$ was platelet-rich plasma (PRP). Just before injection, $0.1 \mathrm{ml}$ of calcium chloride was added for each $1 \mathrm{ml}$ of PRP to activate the platelets. PRP was injected intradermally through a $30 \mathrm{G}$ needle (insulin syringe) in each $\mathrm{cm}^{2}$ melasma.

In group $B$, an insulin syringe was used with a volume of $1 \mathrm{ml}$, containing $0.04 \mathrm{ml}$ ( 4 units of insulin) of TA and the remainder being normal saline: thus each insulin syringe contains $4 \mathrm{mg}$ tranexamic acid (TA). Inj tranexamic acid was injected intradermally through a $30 \mathrm{G}$ needle in each $\mathrm{cm}^{2}$ melasma. In both the groups, the treatment was offered every $4^{\text {th }}$ week and for a total period of 12 weeks; and final outcome was seen at $24^{\text {th }}$ week. At every visit, the cases were noted for their mean MASI score.

The data was entered and analysed with the help of SPSS version 24.0 Frequencies and percentages were calculated for categorical data and mean and standard deviation for numerical data. Independent sample t-test was used for numerical data and Chi-square and Fischer's Exact t-test for categorical data and post stratification. A p value of 0.05 or less was considered significant.

\section{RESULTS}

There were 64 cases, 32 in each group, with 19 (59.38\%) males in group $A$ and $16(50 \%)$ in group $B(p=0.61)$. Mean age in group $A$ and $B$ was $24.63 \pm 9.87$ vs. $23.94 \pm 8.93$ years $(p=0.76)$. The mean duration of melasma was $6.69 \pm 1.25$ months in group $A$ and $5.09 \pm 1.33$ in group $B(p=0.65)$ as in Tablel.

Table I: Demographics ( $n=32$ each).

\begin{tabular}{|l|c|c|c|}
\hline Study variables & Group A & Group B & p \\
\hline Age (years) & $24.63 \pm 9.87$ & $23.94 \pm 8.93$ & 0.76 \\
\hline BMI $\left(\mathrm{kg} / \mathrm{m}^{2}\right)$ & $24.66 \pm 4.11$ & $25.72 \pm 2.89$ & 0.37 \\
\hline Duration of melasma (months) & $6.69 \pm 1.25$ & $5.09 \pm 1.33$ & 0.65 \\
\hline Gender & & & \\
Male & $19(59.38 \%)$ & $16(50 \%)$ & 0.61 \\
Female & $13(40.62 \%)$ & $16(50 \%)$ & \\
\hline
\end{tabular}

Table II: Comparison of mean MAASI score ( $n=32$ in each group).

\begin{tabular}{|l|c|c|c|}
\hline MAASI & Group A & Group B & p \\
\hline Pre-treatment & $29.84 \pm 5.14$ & $29.56 \pm 4.39$ & 0.21 \\
\hline 4 weeks & $29.44 \pm 5.35$ & $28.69 \pm 4.10$ & 0.01 \\
\hline 8 weeks & $25.47 \pm 3.89$ & $24.00 \pm 2.79$ & 0.12 \\
\hline 12 weeks & $12.81 \pm 1.78$ & $18.38 \pm 3.50$ & 0.0001 \\
\hline 24 weeks & $8.72 \pm 3.40$ & $14.97 \pm 4.33$ & 0.02 \\
\hline
\end{tabular}

Mean MAASI score at baseline was $29.84 \pm 5.14$ vs. $29.56 \pm 4.39$ with $p=0.21$. MAASI was significantly better in group $A$ at 4 weeks where score was $29.44 \pm 5.35$ vs. $28.69 \pm 4.10(p=0.01)$ as in Table II. There was no significant difference in both groups at 8 weeks. Mean MAASI at 12 weeks was $12.81 \pm 1.78$ vs. 18.38 $\pm 3.50, p=00001$; and at 24 weeks, it was $8.72 \pm 3.40$ vs. 14.97 \pm 4.33 with $p=0.02$ in group $A$ and B respectively as in Table ll. 


\section{DISCUSSION}

Melasma is a hyper melanotic disorder and can be of great concern due to cosmetic disfigurement. ${ }^{13}$ There are number of treatment modalities with different degree of benefits and untoward effects. ${ }^{14}$ The major concern regarding management is longer duration of therapy and compliance. Tranexamic acid is the most commonly used agent, while platelet-rich plasma has shown promising results. ${ }^{15-17}$

In the present study, regarding comparison of these two, PRP has shown significantly better results at 4 weeks, 12 weeks and 14 weeks; and it was even better at 8 weeks, but that result was statistically significant.

Ciccon A et al. injected PRP on one side of the face and tranexamic acid on the other, and assessed for intra-group pre- and post-procedure outcome; and they revealed that TA-treated side, had statistically significant difference in modified melasma area and severity index (MMASI) from baseline to post-treatment $(6.92 \pm 5$ to SD $2.83 \pm 2.97)$. Out of all their patients, $4(17.4 \%)$ demonstrated moderate improvement, 8 (34.8\%) showed good improvement, and 11 patients (47.8\%) showed excellent improvement. ${ }^{12}$ Similarly, on the PRP-treated side, investigators also noted a statistically significant difference in MMASI from baseline to post-treatment (SD 7.54 \pm 4.67 to SD $4.6 \pm 3.41)$. Of the patients, $2(8.7 \%)$ showed no improvement, 3 (13\%) showed poor improvement, 8 (34.8\%) showed moderate improvement, 7 (30.4\%) showed good improvement, and $3(13 \%)$ showed excellent improvement and over all on one to one comparison PRP was better than tranexamic acid. ${ }^{12}$

Gamea et al. compared tranexamic acid alone vs. tranexamic acid plus PRP. Both groups showed significant improvement of MMASI score after treatment. Significantly better treatment response and patient satisfaction were detected in patients of group $B(p=.024, .029){ }^{18}$

Steiner et al. compared topical and injectable tranexamic acid for melasma. They used photographic evaluation to look for various clinical responses and it was seen that in half of their cases, worsening of the lesions was noted. While, in $37.5 \%$ of the cases, no significant change was observed, and clinical improvement was observed in only $12,5 \%$ of the subjects. In contrast to one to one group comparison, intra-group analysis showed a significant improvement $(p=0.0026)$, with no difference between treatments $(p=0.6512){ }^{19}$

Patil et al. compared three groups, i.e. intradermal tranexamic acid alone (TA), topical TA and combination of three agents, i.e. hydroquinone $2 \%$, tretinoin, and fluocinolone. They found that MASI score decreased in all three groups, but it was statistically significant in group A (TA group) that had the least MASI score followed by triple combination therapy. ${ }^{20}$

Faiza et al. in a study from Pakistan revealed that out of their 15 cases managed with PRP, 2 (13.3\%) has shown good, 9 (60\%) fair and, 4 cases had poor response; and they didn't found significantresponse in any of their cases. ${ }^{21}$
Farag et al. compared dermapen using PRP vs. dermapen using tranexamic acid in cases suffering from melasma on top of renal failure having duration of melasma from one to ten years. They found that PRP was significantly better than tranexamic acid in terms of reduction of lesions with $p=<0.05 .^{22}$

\section{CONCLUSION}

Intradermal PRP is significantly better than intradermal tranexamic acid in the management of melisma; especially, in the longer term. Hence, PRP and good compliance can reduce the disease significantly as compared to conventional tranexamic acid.

\section{LIMITATIONS OF THE STUDY:}

There were many strengthening points of the study as the authors compared one of the most commonly used drug to the newer PRP and also followed up the cases with various regular interval for six months. The limitation of this study was that the authors didn't categorise the cases in terms of mild, moderate and excellent responses. Furthermore, we didn't look for the side effect profiles of these agents as well as patients' satisfaction was not addressed with anyone of these two agents.

\section{ETHICAL APPROVAL:}

Ethical approval was taken from Institutional Review Board, Sheikh Zayed Hospital, Rahim Yar Khan, prior to the initiation of the study.

\section{PATIENTS' CONSENT:}

Informed consents were obtained from patients to publish the data concerning this case.

\section{CONFLICTOF INTEREST:}

The authors declared no conflict of interest.

\section{AUTHORS' CONTRIBUTION:}

MM: Literature review, article writing, design, conception, data collection, analysis.

TH, MKS: Conception, design, analysis.

$\mathrm{NH}$ : Study design.

SA, SR: Conception.

\section{REFERENCES}

1. Sofen B, Prado G, Emer J. Melasma and post inflammatory hyperpigmentation: management update and expert opinion. Skin Therapy Lett 2016; 21(1):1-7.

2. Handel AC, Miot LDB, Miot HA. Melasma: A clinical and epidemiological review. An Bras Dermatol 2014; 89(5): 771-82. doi: 10.1590/abd1806-4841.20143063.

3. Jang YH, Lee JY, Kang HY, Lee ES, Kim YC. Oestrogen and progesterone receptor expression in melasma: an immunohistochemical analysis. J Eur Acad Dermatol Venereol 2010; 24(11):1312-6. doi: 10.1111/j. 14683083.2010.03638.x.

4. Handel AC, Lima PB, Tonolli VM, Miot LD, Miot HA. Risk factors for facial melasma in women: A case-control study. Br J Dermatol 2014; 171(3):588-94. doi: 10.1111/ bjd.13059.

5. Niwano T, Terazawa S, Nakajima H, Wakabayashi $Y$, 
Imokawa G. Astaxanthin and withaferin a block paracrine cytokine interactions between UVB-exposed human keratinocytes and human melanocytes via the attenuation of endothelin-1 secretion and its downstream intracellular signaling. Cytokine 2015; 73(2):184-97. doi: 10.1016/ j.cyto. 2015.02.006.

6. Ortonne JP, Arellano I, Berneburg M. A global survey of the role of ultraviolet radiation and hormonal influences in the development of melasma. J Eur Acad Dermatol Venereol 2009; 23(11):1254-62. doi: 10.1111/j.1468-3083.2009. 03295.x.

7. Vinay K, Bishnoi A, Parsad D, Saikia UN, Sendhil Kumaran M. Dermatoscopic evaluation and histopathological correlation of acquired dermal macular hyperpigmentation. Int J Dermatol 2017; 56(12):1395-9. doi: 10.1111/ijd.13782.

8. Frelinger AL, Torres AS, Caiafa A, Morton CA, Berny-Lang MA, Gerrits AJ, et al. Platelet-rich plasma stimulated by pulse electric fields: Platelet activation, procoagulant markers, growth factor release and cell proliferation. Platelets 2016; 27(2):128-35. doi: 10.3109/0953 7104. 2015.1048214.

9. Kim D, Park S, Park K. Transforming growth factor- $\beta 1$ decreases melanin synthesis via delayed extracellular signal regulated kinase activation. Int J Biochem Cell Biol 2004; 36(8):1482-91. doi: 10.1016/j.biocel.2003.10.023.

10. Cheng J, Vashi NA. Treatment strategies for hyperpigmentation. Dermatoanthropol Ethnic Skin Hair 2017; 2017:417-36.

11. Pandya AG, Hynan LS, Bhore R, Riley FC, Guevara IL, Grimes $P$, et al. Reliability assessment and validation of the Melasma Area and Severity Index (MASI) and a new modified MASI scoring method. J Am Acad Dermatol 2011;

64(1):78-83. doi: 10.1016/j.jaad.2009.10.051.

12. Bala HR, Lee S, Wong C, Pandya AG, Rodrigues M. Oral tranexamic acid for the treatment of melasma: A review Dermatol Surg 2018; 44(6):814-25. doi: 10.1097/ DSS.0000000000001518.
13. Eppley BL, Pietrzak WS, Blanton M. Platelet-rich plasma: A review of biology and applications in plastic surgery. Plast Reconstr Surg 2006; 118(6):147e-159e. doi: 10.1097/ 01.prs.0000239606.92676.cf.

14. Yun WJ, Bang SH, Min KH, Kim SW, Lee MW, Chang SE. Epidermal growth factor and epidermal growth factor signaling attenuate laser-induced melanogenesis. Dermatol Surg 2013; 39(12):1903-11. doi: 10.1111/dsu.12348.

15. Yalamanchili R, Shastry V, Betkerur J. Clinicoepidemiological study and quality of life assessment in melasma. Indian J Dermatol 2015; 60(5):519. doi: 10.4103/ 0019-5154.164415.

16. Rajaratnam R, Halpern J, Salim A, Emmett C. Interventions for melasma. Cochrane Database Syst Rev 2010: 7(7):CD003583. doi: 10.1002/14651858.CD003583.pub2.

17. Cicconr A. Tranexamic acid more effective than plateletrich plasma for melasma treatment. Proc Am Acad Dermatol Mar 02 2019; Washington, USA.

18. Gamea MM, Kamal DA, Donia AA, Hegab DS. Comparative study between topical tranexamic acid alone versus its combination with autologous platelet rich plasma for treatment of melasma. J Dermatol 2020; 2020:e1781755. doi: 10.1080/09546634.2020.1781755.

19. Steiner D, Feola C, Bialeski N, Silva FA. Study evaluating the efficacy of topical and injected tranexamic acid in treatment of melasma. Surg Cosmetic Dermatol 2009; 1(4):174-7.

20. Patil SS, Deshmukh AR. Comparative study of efficacy of intradermal tranexamic acid versus topical tranexamic acid versus triple combination in melasma. Pigment Int 2019; 6(2):84-95.

21. Faiz F, Shehzad A, Farooq R, Mufti S, Nasir A, Ahmad TJ. Efficacy of platelet-rich plasma in the treatment of melasma: A pilot study. J Pak Assoc Dermatol 2017; 28(3):348-53. doi: 10.1111/jocd.13157.

22. Farag MM, Mostafa FF, Gharib KM. Therapeutic effect of dermapen with PRP versus dermapen with tranexamic acid in melasma cases. Zagazig Uni Med J 2020; 2020:1791. 